\title{
Tiered Learning Technology for Competitive Experts in Agricultural Industry
}

\author{
M.V. Vinogradova \\ Federal State Budgetary Educational \\ Institution of Higher Education \\ «Northern Trans-Ural State Agricultural University» \\ Department of Mathematics and Computer Science \\ Tyumen, Russia \\ Vinmarvlad@yandex.ru
}

\author{
L.I. Iakobiuk \\ Federal State Budgetary Educational \\ Institution of Higher Education \\ «Northern Trans-Ural State Agricultural University» \\ Department of Mathematics and Computer Science \\ Tyumen, Russia \\ Lyakobuk@yandex.ru
}

\begin{abstract}
The paper presents the experience of tiered learning technology in the training of competitive experts for agricultural industry. It provides the author's approach to this technology in the study of mathematics, proposes three differentiation levels taking into account proficiency and professional orientation of students. The focus is placed on the use of tiered learning technologies in practical training and knowledge assessment. The paper also defines the need for tiered learning technology and its value in the training of competitive experts.
\end{abstract}

Keywords: competitiveness, student, tiered learning, pedagogical technologies, educational differentiation, learning technology

\section{INTRODUCTION}

In today's conditions the employers impose higher requirements to future experts, their intellectual, moral, and professional development [1].

Besides, the change of all spheres of human activity imposes new requirements to higher education. Therefore, one of the key tasks of modern higher educational institutions is to create conditions for further development of a competitive expert. Any higher educational institution is a social institute where each student shall reach its plenitude as a unique personality. The success of professional education lies in a certain 'readiness' for any activity [2].

It is impossible to train all students within a certain discipline so that they all have the same high level of knowledge since quite often such level cannot be achieved by many students. This means that the majority of them will likely develop a negative attitude to education in general. When studying this problem, the authors faced a need to understand the efficiency of tiered learning technology.

Tiered learning is a pedagogical technology, which implies different levels of acquiring a course content, i.e. the depth and complexity of the same training material may be different but not below basic [3].

Pedagogical technologies represent a set of methods and tools used to process, present, change, and disclose educational information. Pedagogical technologies may be considered as a science on methods of teacher's influence on students in the process of training using the necessary technical or information teaching aids.

Any pedagogical technology: 1) represents a special set of methods, means, approaches and aids ensuring efficiency and stability of the process aimed at guaranteed achievement of the learning objective; 2) is merely a part of the integrated pedagogical (didactic) system answering a question - 'how to teach?', or, to be exact, 'how to ensure efficient learning outcomes?'; 3) suggests multi-objective optimization of educational process under restrictions, maximum training performance (in terms of quality, volume, etc.) at minimum labor, time and material costs; 4) implies diagnosticity and possibility to adjust the educational process; 5) ensures the possibility of its reproduction and repetition by other teachers.

The most important stages of pedagogical technology design are as follows: 1) setting the diagnostic objectives in education; 2) planning the hierarchy and sequence of technological educational operations in space and time; 3) developing criteria for education quality assessment; managing educational cognitive activity through complex descriptions and controllable parameters [3].

Content, methods and teaching aids in pedagogical technologies are interconnected and interdependent. Pedagogical skills of a university teacher is the choice of desirable content of the best methods and aids according to the curriculum and learning objectives. The most essential features typical for pedagogical technology include diagnostic goal-setting, efficiency, designability, integrity, manageability.

The technology of students' training is an independent branch of science on education with its object, subject, theoretical, scientific and methodical principles. The achievements in the field of pedagogics, psychology, social studies, pedagogical experience serve the source of pedagogical technology.

The success of a pedagogical system implies thorough teaching technology of all its components. Any modern pedagogical technology represents the synthesis of pedagogical science and practice, combination of traditional 
elements of the past experience and outcomes of social progress, humanization and democratic transition of a society.

The same technology may be presented in a different manner, and the result obtained from various teachers will be different but close to an average coefficient characterizing this technology. The personal component of teacher's activity, students' cohort features, their general mood and psychological climate inevitably influence the result [4].

The analysis of psychology and pedagogical literature showed that many researchers were designing the levels of acquiring a learning material. These are foreign and domestic authors: B. Bloom, B. Masia, V.P. Bespalko, P.S. Ilyushin, V.G. Korolyeva, V.N. Maximova, M.N. Skatkin, V.P. Simonov, V.M. Sokolov, etc. Many of them suggest almost the same three levels of acquiring a learning material: 'knowledge', 'understanding', 'application'. V.G. Korolyeva, V.P. Bespalko and V.N. Maximov propose four levels of acquiring a learning material. However, the fourth level (V.G. Koroleva, V.P. Bespalko) is similar to the others. V.P. Simonov and M.N. Skatkin propose five levels of acquiring a learning material.

Not many researchers were engaged in designing the tiered learning. One of them is Bukharkina M.Yu., who applied technology of tiered differentiation in teaching and learning at a secondary school. She compares internal and external differentiation. The internal differentiation is understood as the organization of educational process that considers students' individual peculiarities in a classroom. In this case the differentiation of education is very similar to individualization of learning. The external differentiation implies that students with different levels of proficiency are deliberately united into study groups [5]. Erentuyeva A.Yu. considered tiered learning as a way to implement the differentiated approach to students [6]. Teplaya N.A. was studying the tiered system of information culture among engineering students in the conditions of continuous education [7], etc.

Tiered learning is ensured not due to the reduction of studied information but due to the focus on various requirements to its acquisition.

Tiered learning enables a student to use his potential to the maximum. Tiered differentiation provides an opportunity for a teacher to focus on different categories of students [8].

\section{SUBJECTS AND METHODS}

The study was conducted at the Northern Trans-Ural State Agricultural University in 2017-2018 academic year with the participation of students studying Forestry and Wood Processing Technology (35.03.02) and Veterinary-Sanitary Inspection (36.03.01). Sixty students took part in the experiment. The experiment was held during classes in mathematics. The following were used as the methods of study: analysis of materials on psychology, pedagogy and methodology concerning a research topic, generalization of concepts and categories; qualitative and quantitative analysis of obtained data; methods of statistical data processing.
Mathematical education is not only the acquisition of ways and norms of mathematical activity and professional values, but also the introduction to the mathematical culture as part of the universal culture, intellectual development, formation of certain spiritual-moral ideals and axiological orientations [9].

The change of the attitude of young people to mathematics and knowledge in general forces teachers and scientists to search for new learning approaches. There is a need to shift the focus of teaching mathematics at an agricultural university from theory to practice [10].

We suggest identifying three levels of differentiation in the study of mathematics at the university taking into account proficiency and professional orientation:

- Sufficient level: gives the lower boundary of knowledge taking into account the requirements of the Federal State Educational Standard of Higher Education.

- Average level: expands the material of the first level, increases the volume of information and provides for deeper understanding of the main material. It requires profound knowledge of the conceptual framework and ability to solve problems within the studied discipline taking into account professional orientation.

- High level: significantly deepens the knowledge on the material, gives its logical justification, opens prospects to the development of creative thinking. It gives students the opportunity to solve and compose professional tasks independently within the studied discipline.

The efficiency of the tiered learning technology requires a special emphasis on the proficiency level within a subject (students' knowledge, abilities, skills).

The given technology implies the following components (blocks):

1. target- and task-focused technology block;

2. content-based technology block (what to teach);

3. test- and technology-based block that includes a set of diagnostic tools aimed to assess the effects of technology and to describe methods implemented by the given technology (how to teach);

4. sequence of technology implementation stages.

\section{A. Characteristic of the target- and task-focused technology block.}

The objective is to get a conscious idea of the final result regarding a certain activity. The learning objective describes the planned learning outcome. The main pedagogical function is the anticipation of learning outcomes.

The objective of tiered learning technology is to ensure the acquisition of knowledge by students within immediate development taking into account their personal attributes. 
The learning tasks represent the outcomes of objective specification and explicitation. The tasks shall be diagnostic and formulated "in a language of observed actions", i.e. through learning outcomes expressed in students' actions. The learning tasks include the description of two aspects: 1) content; 2) planned quality level of acquiring the output knowledge, abilities, skills within the volume of a studied discipline.

The tiered component of a task-based block implies the achievement of the necessary proficiency level and is included into the content-based block.

The tiered learning poses the following tasks:

Motivation and encouragement for successful learning.

Independent work at various levels.

Knowledge assessment.

\section{B. Characteristic of the content-based technology block}

The content of educational process answers a question: what to teach students in the course of acquiring a learning material. The traditional system of professional education describes content as the system of knowledge, abilities and skills to be acquired by students while studying a certain discipline within a certain professional field and at a certain educational institution. Modern competence-based approaches also imply readiness and ability of students to perform certain actions in particular situations.

Therefore, the content of modern professional education within a specific discipline shall be diagnostic and be fully focused on profession.

\section{Characteristic of the test-and technology-based block}

Within the given technology the organizational modes of study are presented as follows: 1) practical training; 2) independent work (tests in classrooms, professional problems, homework). They foster systematization and reconsideration of individual practical experience, self-assessment within a discipline, awareness of interrelations between various course elements and their integration.

Let us consider the system of actions of a teacher and a student by implementing the tiered learning technology in mathematics.

At the first preliminary stage, having analyzed the results of entrance tests in mathematics, the teacher defines actions of sufficient, average and high levels of knowledge acquisition.

The pie chart shows how (in percentage terms) students are distributed by levels: $21 \%$ assessed their knowledge as sufficient; $64 \%$ - assessed it as average and $15 \%$ - as high (Fig. 1).

At the second diagnostic stage, the teacher develops test cases similar to problems of basic and advanced parts of the unified state examination in mathematics to check the residual knowledge of a school course thus defining the level of knowledge acquisition. As a result of diagnostics, the students pick the learning level of a given subject taking into accouont their interests. Following the diagnostics, the students are split into subgroups.
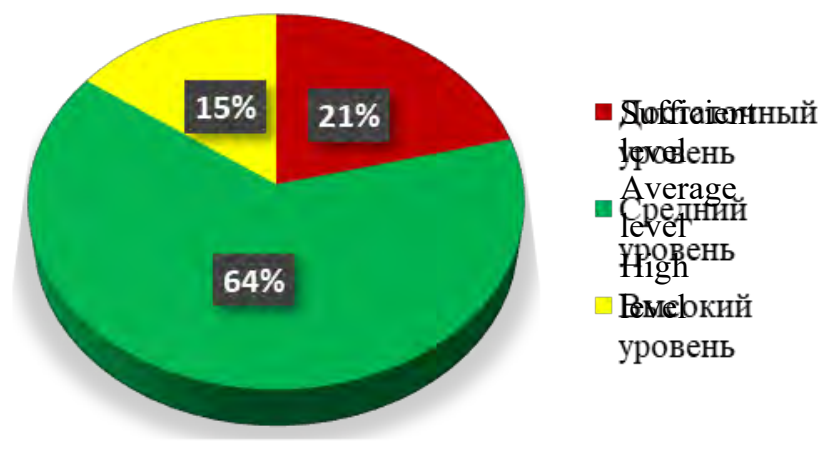

Fig. 1. Distribution of students by levels during entrance tests

The third stage implied the implementation of the tiered learning technology. Students arrange their educational activity within the chosen group.

At the fourth stage of assessing the learning outcomes within the tiered learning technology the teacher assesses the actions of students.

As a result of knowledge diagnostics the group of students is split into subgroups according to sufficient, average and high levels of knowledge. Students do not feel uncomfortable to find themselves in the first, second or third subgroup because they are realistic about their potential and they have a chance to move from one level to another during the entire period of study.

Work with students in subgroups is generally carried out during consolidation of the studied material, knowledge assessment and homework.

At the stage of consolidation of the studied material, the students of average and high levels solve problems independently by using lectures, methodical materials and consulting with the teacher during the first half of a class. The students of sufficient level study through teacher-centred approach, solve problems following a pattern, receive recommendations and help.

During the second half of a class the students of average and high levels solve problems of different levels of complexity, including problems of professional direction. The students of sufficient level independently solve standard problems following a pattern and simple problems of professional direction.

Such educational process motivates students for good academic progress, there is an element of competition both among fellow students and with yourself.

The current state of studying disciplines provides for a new look at the assessment of learning efficiency [11]. At the assessment stage everyone gets the same exam problems, 
which are distributed by complexity. The assessment criteria are explained at the beginning of a test. The test results are shared at the next class with their further analysis during consultations.

The study shows that the problem of learning efficiency may only be solved successfully provided the high quality of classes is supported by well-organized homework. No matter what is the efficiency of classes the concentrated memorization and knowledge are only stored in immediate and short-term memory. To transfer them into the long-term memory the students shall repeat them subsequently, which can be done through homework.

It is advisable to use the tiered approach to differentiated hometasks. According to Verbitskaya N.V., the repetition of the same tasks by advanced students that acquired certain skills is the underestimated requirement [12]. It would be better to give them advanced tasks instead of obligatory homework. Such tasks contribute to the development of their abilities and expand their knowledge. Thus, the students with high level of proficiency may be given problems of professional direction on a particular subject as homework.

Reproductive tasks shall be given to students with the average level of proficiency. The students with sufficient level receive detailed instructions to the task performed following a pattern.

It is also suggested to give additional tasks to students. The 'lagging behind' students may be given tasks to eliminate their knowledge gaps, while 'talented' students may solve problembased tasks to develop their creative abilities and inclinations, and the others may be given training exercises to develop certain practical skills and abilities. It is possible to offer students additional home tasks to be solved if desired. It is obligatory to stimulate them on their performance and to encourage them if they did an optional task. This provokes keen interest in a subject.

It is critical to select proper teaching materials [13], since the interest in receiving higher education and acquiring future profession depends on its content [14]. The learning content and form also affect the values of students [15].

Summarizing the above, the tiered learning technology can be presented in the form of a flowchart (Fig. 2).

The use of tiered learning technology in mathematics provoked high intellectual and emotional activity among students. All students demonstrated high interest in obtaining sufficient level of knowledge within a discipline, and the tasks of different levels of complexity motivated them for good academic progress. This, in turn, fostered some passion and stimulated psychological activity among students.

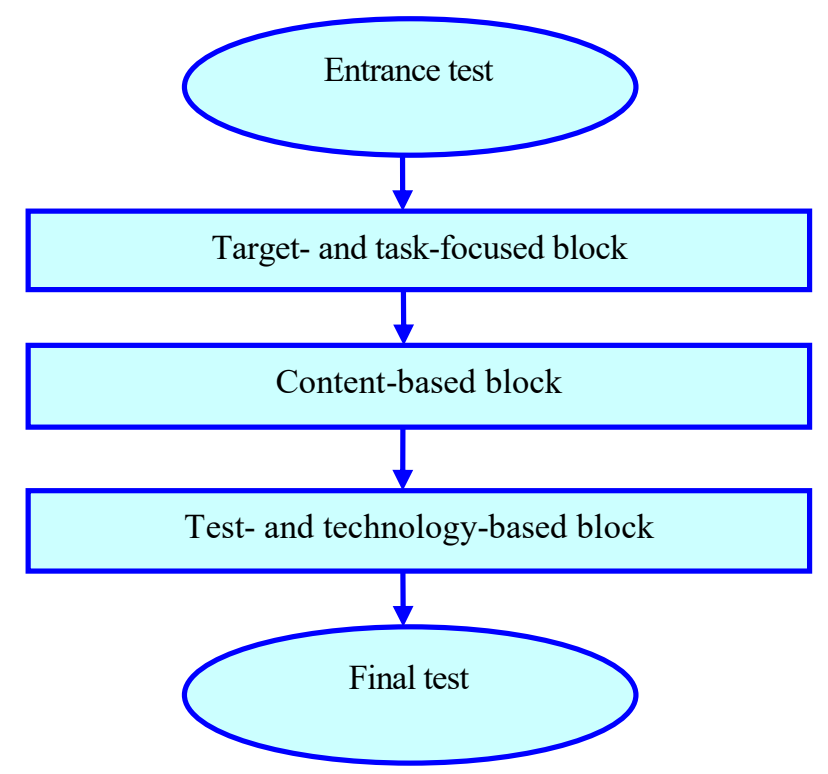

Fig. 2. Flowchart of tiered learning technology

\section{RESULTS}

During the survey regarding the question "Your attitude to tiered learning technology", some students said that "we are proud of ourselves" if they were able to solve problems of higher level than that, which was defined at the diagnostics stage. The others said that "problems of different levels allow to be realistic about your potential and avoid celebrating your success compared to students lagging behind in a discipline". The third ones showed great interest in problems of professional direction, and not only in the solution of such tasks, but also in their preparation, which contributed to their understanding of mathematics.

Thus, this technology helps to increase the level of knowledge by triggering the cognitive interest to mathematics and by understanding the importance of the subject material in practice [16].

The results of the experiment allowed establishing considerable change of students' attitude to learning. The students began to ask more questions, completeness and quality of homework increased alongside with the number of students using additional sources of information to solve problems in mathematics. The bigger number of students became interested in additional tasks thus increasing the initiative and independence of acquiring a learning material, which improved the general progress within a course.

The below pie chart shows how (in percentage terms) students are distributed by levels during final assessment: $11 \%$ assessed their knowledge as sufficient; $65 \%$ - assessed it as average and $24 \%$ - as high (Fig. 3). 


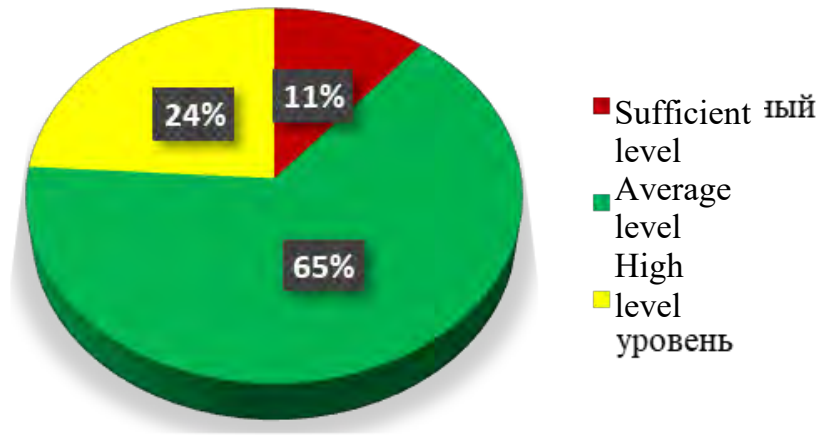

Fig. 3. Distribution of students by levels during final assessment

Thus, the knowledge assessment at the final stage demonstrates the change of the number of students that managed to improve their level of proficiency.

\section{CONCLUSIONS}

The important condition of the tiered learning technology is continuous work with students through joint agreement on the following:

every student may choose the level of acquiring a learning material (not below basic);

the main emphasis in learning is placed on individual independent work combined with problems of professional direction;

before getting to a new topic, students become aware of its objectives and final learning outcomes;

the acquisition of a learning material is assessed through exams and home tasks containing problems of different levels of complexity and through independent preparation of problems of professional direction.

Thus, the tiered learning technology made it possible for every student to feel comfortable during classes. Some try to acquire the sufficient level of knowledge, the second ones the average, and the third - seek to reach the high level of acquiring a learning material in mathematics and learn to solve problems of professional direction. The main aspect is that they are able to assess their potential and opportunities independently. All of the aforesaid ensures the necessary preparation of young people for continuous educational activity and develops their readiness for self-education and self-development

[17].

\section{References}

[1] M.V.. Vinogradova, "Use of interdisciplinary communications in the training of competitive experts in agricultural engineering”, Agrofood policy of Russia, vol. 12 (72), pp. 165-168, 2017

[2] D.V. Eryomina, «Applied informatics for experts of agricultural sector», Agrofood policy of Russia, vol. 9 (69), pp. 98-103, 2017.

[3] L.I. Iakobiuk, "Development of professional competencies of future managers on the basis of professional software tools", Cand. Sci. Dissertation, Tyumen, 2011, pp. 213.

[4] N.E. Kasatkina, T.K. Gradusova, T.A. Zhukova, E.A. Kagakina, O.M. Kolupayeva, G.G. Solodova, I.V. Timonina, Modern educational technologies at higher educational institution, Kemerovo: KRIRPO State Educational Institution, 2011, pp. 237.

[5] M.Yu. Bukharkina, "Tiered education technology. Article. Foreign languages at school", Scientific and methodical journal, vol. 3, pp. 11$12,2003$.

[6] A.Yu. Erentuyeva, Tiered education as a way to implement differentiated approach to students: extended abstract of Cand. Sci. (Padagogy) Dissertation, Ulan-Ude: BSU, 1997, pp. 20.

[7] N.A. Teplaya, Tiered system of information culture development among engineering students within continuous education: extended abstract of Cand. Sci. (Padagogy) Dissertation, Shuya, pp. 50, 2016.

[8] S.V. Kulikova, "Professional self-determination as a factor influencing the development of professional competencies of university graduates", Agrofood policy of Russia, vol. 5 (17), pp. 60-64, 2014.

[9] N.V. Biryukova, "Model of personal meaning of studying mathematics among students of non-core disciplines", Agrofood policy of Russia, vol. 12 (72), pp. 161-164, 2017.

[10] N.N. Malchukova, S.V. Kulikova, "Improvement of academic performance in mathematics among students of Agricultural Engineering", Agrofood policy of Russia, vol. 9 (69), pp. 104-108, 2017.

[11] N.E. Otekina, A.A Otekin, Competence approach of computer-based testing in diagnostics of education quality, Problems of value formation in education of rural youth, Proceedings of the International Scientific and Practical Conference, pp. 119-123, 2014.

[12] N.V. Verbitskaya, "Technological and professional education in Russia and abroad as a factor of sustainable development of a society", Novokuznetsk, 2011, Part 1, [Proceedings of the VI International Scientific and Practical Conference "Training of future teachers for professional activity using modern pedagogical technologies"]

[13] Yu.Z. Bogdanova, "Profession-oriented foreign language training at an agrarian higher educational institution", Philological sciences. Questions of theory and practice, vol. 12-2 (78), pp. 194-196, 2017.

[14] S.M. Kayugina, "Motives of choice of higher educational institution and profession, their role in expert's development", ["Problems of value formation in education of rural youth", Proceedings of the International Scientific and Practical Conference., pp. 36-37, 2014].

[15] L.I. Iakobiuk, M.V. Vinogradova , N.N. Malchukova, Y.V. Kryucheva, "Students of agrarian university: social profile in mirror of deviations", ESPACIOS, vol. 38 ( $\mathrm{N}^{\mathrm{o}}$ 40), pp. 17, 2017.

[16] N.V. Biryukova, "The modernization project of the mathematics teaching process providing the formation of a personal sense of knowledge for students of non-core areas", Espacios, vol.39 (20), pp. 4, 2018.

[17] N.N. Malchukova, "Readiness for self-education as a pedagogical problem" [Problems of value formation in education of rural youth, Proceedings of the International Scientific and Practical Conference, 2014, pp. 113-114]. 